\title{
Correction to: Effect of a Focused Social and Communication Intervention on Preterm Children with ASD: A Pilot Study
}

\author{
Álvaro Bejarano-Martín ${ }^{1} \cdot$ Ricardo Canal-Bedia ${ }^{1,4}$ () María Magán-Maganto ${ }^{1}$. Aránzazu Hernández Fabián ${ }^{2}$. \\ Andrea Luz Calvarro Castañeda ${ }^{1}$ - Sara Manso de Dios ${ }^{1}$ - Patricia Malmierca García ${ }^{1}$ - Emiliano Díez Villoria ${ }^{1}$. \\ Cristina Jenaro Río ${ }^{1}$. Manuel Posada de la Paz ${ }^{3}$
}

Published online: 10 June 2021

(c) Springer Science+Business Media, LLC, part of Springer Nature 2021

\section{Correction to: Journal of Autism and Developmental Disorders https://doi.org/10.1007/s10803-021-05068-8}

The original version of the article has a complete wrong title. The correct title of the article has been updated in this erratum.

The correct title is Effect of a Focused Social and Communication Intervention on Preterm Children with ASD: A Pilot Study.

The original article can be found online at https://doi.org/10.1007/ s10803-021-05068-8.

Ricardo Canal-Bedia

rcanal@usal.es

Álvaro Bejarano-Martín

alvaro_beja@usal.es

María Magán-Maganto

mmmaria@usal.es

Aránzazu Hernández Fabián ahernandezf@saludcastillayleon.es

Andrea Luz Calvarro Castañeda andreacc23@usal.es

Sara Manso de Dios sara_mansodedios@usal.es

Patricia Malmierca García pmalmierca@usal.es

Emiliano Díez Villoria emid@usal.es
The Original article has been updated.

Publisher's Note Springer Nature remains neutral with regard to jurisdictional claims in published maps and institutional affiliations.
Cristina Jenaro Río crisje@usal.es

Manuel Posada de la Paz mposada@isciii.es

1 INICO, Instituto Universitario de Integración en La Comunidad, Universidad de Salamanca, 37008 Salamanca, Spain

2 Hospital Clínico Universitario de Salamanca, 37007 Salamanca, Spain

3 Instituto de Investigación de Enfermedades Raras, Instituto de Salud Carlos III, 28029 Madrid, Spain

4 Centro de Atención Integral Al Autismo (INFOAUTISMO), Facultad de Educación, Universidad de Salamanca, Paseo Canalejas, 169, 37008 Salamanca, España 